\title{
Upper and lower face and ideomotor apraxia in patients with Alzheimer's disease
}

\author{
Jay Guido Capone ${ }^{\mathrm{a}}$, Sergio Della Sala ${ }^{\mathrm{b}, *}$, Hans Spinnler ${ }^{\mathrm{a}}$ and Annalena Venneri ${ }^{\mathrm{b}}$ \\ ${ }^{a}$ Third Neurology Ward, San Paolo Hospital, Department of Medicine, Surgery and Dentistry, University of Milan, \\ Milan, Italy \\ ${ }^{\mathrm{b}}$ Neuropsychology Research Group, Department of Psychology, University of Aberdeen, UK
}

\begin{abstract}
Introduction: Apraxia of face movement in Alzheimer's disease (AD) has been rarely investigated. This study aimed at investigating the frequency of lower (mouth, tongue and throat) and upper (eyes and eyebrows) face apraxia, in AD and its relationship with limb apraxia and severity of dementia.

Methods: Fifty seven patients with AD were tested with a new standardised test of face apraxia including upper and lower face movements, which uses an item-difficulty weigthed scoring procedure, the IMA test, a test of ideomotor apraxia and the M.O.D.A., a means to assess dementia severity.

Results: Thirteen (23\%) and 19 (33\%) participants were below cut-off respectively on the upper and lower face apraxia test. Both sections of the Face Apraxia Test correlated significantly with the Ideomotor Apraxia Test. However, double dissociations between different types of apraxia were observed. Both the upper and lower face apraxia tests correlated significantly with the measure of dementia severity.

Conclusions: The finding show that a proportion of AD patients fails face apraxia tests. Their face apraxia is interlinked with ideomotor limb apraxia, although dissociations are possible. Severity of dementia deterioration accounts for a good proportion of the variability of AD patients' performance on face apraxia tests.
\end{abstract}

Keywords: Face apraxia, ideomotor apraxia, Alzheimer's disease

\section{Introduction}

Apraxia generally refers to the impaired ability to perform movements upon request [56]. This impairment should not be accountable for in terms of impairment of motor or sensory functions [13]. The term apraxia usually refers to a variety of disorders which are specified more in detail either referring to the regions of the body affected, or the testing procedures employed or the theoretical framework of reference adopted. Several group studies have reported ideomotor limb apraxia or ideational apraxia in patients with Alzheimer's disease (AD) [20,25,39,69] (review in [57]). Apraxia of face movements in patients with

\footnotetext{
${ }^{*}$ Corresponding author: Prof. Sergio Della Sala, Department of Psychology, University of Aberdeen, King's College, Aberdeen AB24 2UB, UK. E-mail: sergio@abdn.ac.uk.
}

(AD) has, however, received very little attention and its frequency and characteristics have yet to be defined in this patient population.

Face apraxia involves intentional movements of the face muscles [14]. It should be kept separate from "apraxia of speech" [60] and "pure anarthria" [41]; both these disorders result from disturbances of word articulation rather than of oro-facial movements (see reviews in [36] and [59]).

Generally, authors refer to face apraxia as oral apraxia, because, in most instances, only the movements of the lower face are examined $[17,38,58]$. Several papers, however, reported patients with oral apraxia following focal brain lesions who also showed deficits of the movements of the upper part of the face (eyes and eyebrows) (e.g. $[12,36,37,50])$.

Although face apraxia is probably the most frequent of all apraxias due to focal brain lesions [53], it is sel- 
dom assessed in clinical practice and very few controlled experimental studies have been carried out. The dearth of experimental investigations on face apraxia is even more noticeable when one searches for studies of face apraxia in patients with degenerative brain diseases. Face apraxia, either of the lower (e.g. $[2,12,47$, $65,66]$ ) or the upper face (e.g. $[1,35]$ ), has been mentioned in passing in relation to speech impairment in a few cases of patients affected by non-Alzheimer type dementias.

Only a few studies are available in the literature in which face apraxia is reported in AD. Marcuse [40] reported the case of a patient, W., a 60-year old woman with a history of 3-4 years of progressive memory and cognitive deterioration with amnesiac onset, without any apparent neurological sign. This patient showed lower and upper face apraxia; for example, she repeatedly failed to stick out her tongue, wrinkle her forehead or direct her gaze on the horizontal plane on verbal command. Perea and Ladera [48] tested 54 patients with $\mathrm{AD}$ and reported that their poor performance on a scale measuring activities of daily living could be partly accounted for by their low scores on a short test assessing oral apraxia. Kokmen et al. [33] reported findings of a Turkish/American cross-cultural validation study on an apraxia test, which included ten items for the assessment of movements of the lower face, in which responses were scored using a pass/fail criterion (score 1-0). These authors tested also $18 \mathrm{AD}$ patients whose mean score on the oral apraxia items was significantly poorer than that of a group of healthy controls. Rapcsak et al. [55] and Taylor [62] carried out two independent studies whose main focus was to investigate the frequency of lower face apraxia in AD. In both studies a 5-item test was used. Data from these studies yielded fairly contrasting results: Rapcsak et al. [55] stated that less than $20 \%$ of $\mathrm{AD}$ patients were affected by face apraxia, while Taylor [62] maintained that face apraxia was present in over $90 \%$ of the AD patients studied.

Therefore, data on the frequency of face apraxia in $\mathrm{AD}$ are scant and contrasting. Further, issues related to the relationship between face apraxia and dementia severity remain unsettled. Moreover, upper face apraxia has never been investigated in patients with AD. The relationship between limb and face apraxia in patients with focal brain lesions has been matter for debate. Some authors supported a unitary mechanism underlying both deficits, (e.g. [51]), while others maintained that these deficits result from partially independent mechanisms (e.g. [6]) or that they may dissociate completely (e.g. [17,54]). Ideomotor and face apraxia, however, were never directly compared in patients with AD.

Studies with AD patients have already made a substantial empirical contribution to cognitive models in several domains - such as working memory [3,7] face processing [21], language [19,49], visual perception [18,22] and semantic memory [4,29], distribution of attention in space [5,67]. This contribution has added to our understanding of cognitive systems and their anatomical substrates and stems from the uniqueness of the Alzheimer neuropathology that is characterised by a fine grained and diffuse progressive damage of cerebral networks. Traditionally face apraxia has been linked to lesions in the left hemisphere and associated with non-fluent aphasia $[17,46,52,61]$, probably because of anatomical contiguity $[13,63]$. However, more recent findings suggest that damage to a much broader neuronal network, involving both the left and the right hemisphere, may result in lower and upper face apraxia [9]. Therefore, patients with AD, who suffer from a widespread and slowly progressive degeneration are ideal candidates for verifying the hypothesis that a larger network is responsible for face eupraxia.

The aim of this study was to investigate the frequency of lower (mouth, tongue and throat) and upper (eyes and eyebrows) face apraxia in patients with AD using a new standardized test, for which norms collected on a sample of 180 healthy controls are available [23]. This test has also been validated on a group of stroke patients $[9,23]$. A further aim of this study was to clarify the relationship between face apraxia, limb apraxia and severity of dementia as well as verify whether dissociating performances on the two types of apraxia test are present.

\section{Methods}

\subsection{Participants}

Fifty seven out-patients (14 male, 43 female) meeting NINCDS-ADRDA clinical criteria for possible or probable AD [43] were included in the study. These patients were recruited from referrals to the Dementia Neuropsychology Unit of the Third Neurology Clinic, San Paolo Hospital, University of Milan. The age of onset in $15 \%$ of the cases was below 70. A CT (or MRI) brain scan was performed on all the patients. Age in this sample ranged from 51 to 88 years (mean 72.85 , SD 8.48 ). The education range was $1-19$ years (mean 7, SD 3.82). 
Table 1

Number (percentage) of patients whose scores were below cut-off on the face apraxia test and the ideomotor apraxia test

\begin{tabular}{lcrl}
\hline & Mild AD & Moderate AD & Severe AD \\
\hline Upper Face Apraxia Test & $4 / 30(13 \%)$ & $5 / 19(26 \%)$ & $4 / 8(50 \%)$ \\
Lower Face Apraxia Test & $4 / 30(13 \%)$ & $10 / 19(53 \%)$ & $5 / 8(62.5 \%)$ \\
Ideomotor Apraxia Test & $4 / 30(13 \%)$ & $8 / 19(42 \%)$ & $5 / 8(62.5 \%)$ \\
\hline
\end{tabular}

The severity of cognitive deterioration was evaluated using the M.O.D.A (Milan Overall Dementia Assessment [10]), a neuropsychologically-oriented psychometric severity scale. The M.O.D.A. score ranges from 0 (worst score) to 100 (cut-off score $=85.5$, which corresponds to the outer tolerance limit in the normal population). M.O.D.A. raw scores are then adjusted for age and education. M.O.D.A. adjusted scores in this sample ranged from 31.2 to 85.1 (mean 66.99, SD 14.42).

The University of Milan Ethical Committee approved the experiment. All patients and their relatives gave their informed consent to take part in this study.

\subsection{Experimental design}

A correlative design (Pearson coefficients) was used for most of the analyses in this experiment. A within subject design was adopted for comparing performance on the face apraxia and ideomotor apraxia tests. For this latter comparison a medium effect size $(d=0.50)$ was anticipated for the difference in performance between the two tests. Statistical power with a sample of 57 patients was estimated as 0.96 . at $\alpha=0.05$

\subsection{Apraxia tests}

\subsubsection{Upper and lower face apraxia test}

A test of face apraxia devised, standardised and validated in our laboratory $[9,23]$ was used. The Face Apraxia Test includes two separate subtests suitable for the assessment of movements of the upper and lower face. The Upper Face Apraxia Test includes 9 items (e.g., wrinkle forehead; close eyes; blink left eye), while the Lower Face Apraxia Test incorporates 29 items (e.g., stick out tongue; clear throat; make a high tone). Each item was demonstrated by the examiner and the participant had to respond by imitation immediately after presentation. This procedure was adopted to minimise the confusion between apraxic and verbal comprehension errors. Items were scored as pass or fail. For both subtests a difficulty weighted scoring procedure was employed. The relative difficulty of each item had been previously established in the standardis- ation phase by rank ordering the test items according to the total number of failures observed in a sample of 180 normal controls. Additionally, each individual score was also adjusted for age and education effects. In the Upper Face Apraxia Test the score ranges from zero to 45.0; the inferential cut-off score, corresponding to the outer tolerance limit is 38.4 while the inner tolerance limit is 42.3. In the Lower Face Apraxia Test the score ranges from zero to 435.0; the cut-off score is 400.0 and the inner tolerance limit is 419.3. Studies on the normative features of the test $[9,23]$ showed that both subtests have an inter-rater reliability of 0.93 .

\subsubsection{Ideomotor apraxia test}

The test devised by De Renzi et al. [16] was used. This is a 24-item imitation test including an equal number of meaningful and meaningless movements, half requiring the holding of postural gesture and half requiring the execution of a motor sequence. The score for each item ranges from three to zero. A score of three to one is given depending on whether a gesture is performed correctly after the first, second or third attempt. A score of zero is given if the performance is incorrect on all three attempts. The total score ranges from zero to 72. The cut-off score, below which the performance is considered pathological, is 53 [15].

\section{Results}

The results of this study showed that 13/57 (23\%) AD patients scored below cut-off on the Upper Face Apraxia test. A higher proportion of them, 19/57 (33\%), scored below cut-off on the Lower Face Apraxia test. On the Ideomotor Apraxia test 17/57 (30\%) patients had scores which fell below cut-off when their left hand was tested, while a smaller number, 14/57 $(24.5 \%)$, scored below cut-off when their right hand was tested.

A correlation analysis was run to see whether the AD patients' scores on the Face Apraxia test correlate with disease severity as expressed by M.O.D.A. scores. Results showed that there was a significant correlation between scores on the Upper Face Apraxia test and 
the M.O.D.A. scores $(r=0.369, p=0.0045)$ and between scores on the Lower Face Apraxia test and the M.O.D.A. scores $(r=0.537, p<0.0001)$. A significant correlation was also present between the M.O.D.A. scores and scores on the Ideomotor Apraxia test with the right ( $r=0.441, p=0.0005)$ and left hand $(r=0.572, p<0.0001)$ respectively. The scores on the Upper Face Apraxia test correlated significantly with the scores on the Ideomotor Apraxia test both with the right $(r=0.657, p<0.0001)$ and the left $(r=0.622, p<0.0001)$ hand. Similarly the scores on the Lower Face Apraxia test correlated significantly with the scores on the Ideomotor Apraxia test both with the right $(r=0.696, p<0.0001)$ and the left ( $r=0.653, p<0.0001)$ hand.

In order to verify whether there was a larger number of patients falling below cut off in the most severe range, the group of patients was divided in three subgroups according to their M.O.D.A. scores. This was done by calculating the difference between the highest and lowest M.O.D.A. score in the group, and by dividing this difference in three equal intervals. Three severity bands were identified; the original patient group was divided in three subgroups labeled mild if their M.O.D.A. score was between 67.1 and 85.1, moderate if their M.O.D.A. score was between 49.1 and 67.0 and severe if their M.O.D.A. score was between 31.2 and 49.0. The percentage of patients below cut-off for each severity band is shown in Table 1 .

When a single case analysis was carried out, dissociations emerged. Nine patients showed both apraxia of the upper and lower face. Four had apraxia of the upper face but not of the lower face and 10 showed the converse pattern. As for dissociations between face apraxia and ideomotor apraxia (as expressed by the average score between right and left hand), the analysis showed that nine patients had both upper face apraxia and ideomotor apraxia, while 11 patients had both lower face apraxia and ideomotor apraxia. Of 13 patients with upper face apraxia, four did not have ideomotor apraxia, whereas eight out of 19 patients with lower face apraxia did not have ideomotor apraxia. Only two of those patients with both upper and lower face apraxia did not have also ideomotor apraxia. Only three patients who had ideomotor apraxia showed neither upper nor lower face apraxia. Table 2 provides a summary of the observed associations and dissociations between the three types of apraxia.

Raw scores on both the Upper and Lower Face Apraxia Test were combined together and transformed in percentage of correct score to obtain an index of face
Table 2

Number (percentage) of patients without any form of apraxia and who showed dissociations or associations of upper face apraxia (UFA), lower face apraxia (LFA) and ideomotor apraxia (IMA)

\begin{tabular}{lc}
\hline AD Patients & Number \\
\hline Without any form of apraxia & $31(54 \%)$ \\
With some form of apraxia: & $26(46 \%):$ \\
UFA only & $2(8 \%)$ \\
LFA only & $6(23 \%)$ \\
UFA+LFA only & $2(8 \%)$ \\
IMA only & $3(11 \%)$ \\
UFA+IMA only & $2(8 \%)$ \\
LFA+IMA only & $4(15 \%)$ \\
UFA+LFA+IMA & $7(27 \%)$ \\
TOTAL & $\mathbf{5 7}$ \\
\hline
\end{tabular}

apraxia. Raw scores on the Ideomotor Apraxia Test underwent the same transformation to obtain an index of ideomotor apraxia. The transformation in percentage was necessary to eliminate the difference in scale between the two tests. An analysis of variance was run on the transformed scores. This showed a statistically significant difference between hand and face apraxia $\left(F_{(1,56)}=4.742, p=0.0337\right)$ indicating that in this group of AD patients ideomotor apraxia was more severe than face apraxia. The effect size observed was very close $(d=0.48)$ to the one estimated at the inception of the study.

\section{Discussion}

Results from this study show that there is a proportion of $\mathrm{AD}$ patients who fail on face apraxia tests and that dissociations between upper and lower face apraxia or between face apraxia and ideomotor apraxia are present in $\mathrm{AD}$.

Rapcsak et al. [55] found that the $28 \mathrm{AD}$ patients they tested failed only $17 \%$ of the items of their oral apraxia test (compared to performance at ceiling of 23 healthy controls). These authors interpreted their findings as an indication of relative sparing of face apraxia in $\mathrm{AD}$, which would be justified in terms of anatomical segregation. Studies with patients with focal brain lesions have shown that the brain areas involved in lower face apraxia are the frontal and central opercula, the first temporal convolution and the anterior portion of the insula [63], as well as the striatum [44,54]. These regions are not the most damaged by $\mathrm{AD}$ [11]. In contrast to Rapcask et al's findings [55], Taylor [62] reported that $92 \%(23 / 25)$ of his AD patients scored below cut-off in the lower face apraxia test [32] he used. Our data show a different scenario. Both upper and lower face 
apraxia are found with low frequency (13\% for both types of apraxia) in patients in the very mild stage. The frequency of these disorders shows a substantial increase with the progression of the disease moving up to much higher figures $(26 \%$ and $50 \%$ for upper face apraxia and $56 \%$ and $62.5 \%$ for lower face apraxia) as the disease progresses into moderate and severe stages. The anatomical interpretation proposed by Rapcsak et al. [55] is based on the assumption that the degenerative process in $\mathrm{AD}$ does not encroach upon the anterior brain areas responsible for face eupraxia. However, the network involved in face eupraxia might be less localised than previously thought. A recent study confirmed the view that a distributed network in the left hemisphere is involved in face eupraxia and pointed to a role of a similarly distributed network present also in the right hemisphere [9], especially associated with movements of the upper face. The possibility that the right hemisphere plays some role in face eupraxis is supported by evidence of eyelid opening apraxia secondary to right hemisphere infarction [30]. A few studies have also documented that even posterior lesions can cause face apraxia $[8,9,27,28]$. The notion that the network involved in eupraxia is more diffuse than previously thought is supported by further data gathered in AD patients. Foster et al. [26] reported evidence of right parietal lobe activation detected in $\mathrm{AD}$ patients when performing a limb apraxia imitation task. Further evidence of a largely distributed network is provided by the PET findings in a patient with left fronto-parietal dysfunction who showed preserved gesture comprehension [31].

The contrasting findings between studies may be accounted for by differences in severity amongst the patients included. One could assume that the more severe the patients' disease, the more likely it is that the degenerative process involves one or another part of the face eupraxia network. Our data point to this direction. In our sample, the correlation between severity of dementia, as measured by the M.O.D.A., and face apraxia scores accounts for $33 \%$ and $52 \%$ (upper and lower face apraxia respectively) of the variability, indicating that overall cognitive severity does play a role especially in lower face apraxia. These findings, however, are hard to reconcile with those of Rapcsak et al. [55] since the patients included in their study were also relatively severe: their MMSE scores ranged from two to twenty (mean 11.8). Severity alone cannot, therefore, be the only factor to account for the difference in findings between studies. Especially, severity does neither account for the difference between the results in our study and Rapcsak et al's one [55], nor for the difference between this latter and Taylor's study [62]. A more likely explanation may reside in differences between their psychometric choices. While Taylor [62] based his conclusions on the high number of patients failing the entire task, Rapcsak et al. [55] argued for the preservation of face apraxia in AD on the basis of the total count of items failed by the whole group. Had this latter scoring criterion been used, Taylor's [62] patients would have failed only $13 \%$ of the items, proving as "mild" as Rapcsak et al.'s patients. Of course the converse may also be true. Since Rapcsak et al.'s [55] controls performed at ceiling, it is likely that most of their patients would have had scores below cut-off had they used one. One could, therefore, conclude from the available evidence on face apraxia in $\mathrm{AD}$, including the findings of the present study, that, especially in the more severe stage of the disease, there is a significant proportion of $\mathrm{AD}$ patients showing face apraxia.

The proportion of AD patients showing face apraxia (23\% and 33\% for upper and lower face respectively) compares with those having limb ideomotor apraxia, shown by $30 \%$ of the patients in the present study. Both tests had to be performed on imitation and all items were intransitive in both cases; a few meaningful gestures were present in both the face and the limb tests. The proportion of AD patients with limb apraxia observed in the present study reflects that observed in previous investigations (e.g. [20]: 30\%; [70], sample 1: $45 \%$; [34], 36\%). Other researchers however, who also used imitation tests, reported much higher prevalence of ideomotor limb apraxia (e.g. [70], sample 2: $84 \%$; [24], 94\%). Heterogeneity amongst different psychometric properties of the various measures of limb apraxia (number of items, selection of cut-off point) used in all different studies may account for part of the discrepancy among investigations.

As for face apraxia, our data show that the proportion of patients with ideomotor apraxia increases significantly with disease severity ranging from $13 \%$ in the mild subgroup to $42 \%$ in the moderate, to $62.5 \%$ in the more severe one. Edwards et al. [25] subdivided AD patients in different stages of dementia severity and reported an increasing frequency of limb apraxia, which ranged from 35 to $98 \%$, as dementia severity increased. Accordingly, Travniczek-Marterer et al. [64] found that performance on ideomotor limb apraxia tests begins to deteriorate in the early stages of the disease. The rate of progression of ideomotor limb apraxia is very slow. Della Sala et al. [20] followed 18 patients with AD longitudinally for seven months and found that only two 
patients, who were not apraxic on the first instance, performed below cut-off at re-test.

In the present study, face and limb apraxia showed high intercorrelations. In addition to severity, ideomotor apraxia accounts for $68 \%$ of the variability on the Upper Face Apraxia test and for $72 \%$ of the variability on the Lower Face Apraxia test. Some dissociations were, however, present either between upper and lower face apraxia or between face apraxia (upper, lower or both) and ideomotor apraxia. Dissociations between face apraxia and ideomotor apraxia have been previously reported $[6,17,42,45,68]$. The presence of dissociations gives the opportunity for cognitive speculations. Among the possible models of apraxia a dichotomy between unitary versus non-unitary models has been postulated [54]. The unitary model would not support the presence of dissociating performance between different types of apraxia, whilst the non-unitary one would account for dissociations. Our findings of several dissociations support a separable model. However, given the frequency of concomitant ideomotor and facial apraxia both in patients with focal brain lesions (e.g. 72\% in De Renzi et al.'s sample [17]) and in our own sample of patients with AD, the hypothesis of partially overlapping systems seems the most plausible.

\section{Acknowledgement}

This study was partially supported by $60 \%$ MURST 1997 and 1998 grant to HS

\section{References}

[1] J.C. Adair, D.J.G. Williamson and K.M. Heilman, Eyelid opening apraxia in focal cortical degeneration, Journal of Neurology, Neurosurgery and Psychiatry 58 (1995), 508-509.

[2] P. Azouvi, C. Bergego, L. Robel, N. Marlier, I. Durant, J.P. Held and B. Bussel, Slowly progressive apraxia: two case studies, Journal of Neurology 240 (1993), 347-350.

[3] A.D. Baddeley, S. Della Sala and H. Spinnler, The twocomponent hypothesis of memory deficit in Alzheimer's disease, Journal of Clinical and Experimental Neuropsychology 13 (1991), 341-349.

[4] R. Barbarotto, E. Capitani, H. Spinnler and C. Trivelli, Slowly progressive semantic impairment, Neurocase 1 (1995), 107119.

[5] P. Bartolomeo, G. Dalla Barba, M. F. Boisse, A.C. BachoudLevi, J.D. Degos and F. Boller, Right-side neglect in Alzheimer's disease, Neurology 51 (1998), 1207-1209.

[6] A. Basso, E. Capitani, S. Della Sala, M. Laiacona and H. Spinnler, Recovery from ideomotor apraxia: a study on acute stroke patients, Brain 110 (1987), 747-760.
[7] J.T. Becker, Working memory and secondary memory deficits in Alzheimer's disease, Journal of Clinical and Experimental Neuropsychology 10 (1988), 739-753.

[8] F. Benson, W. Sheremata, R. Bouchard, H. M. Segarra, D. Price and N. Gerschwind, Conduction aphasia: A clinicopathological study, Archives of Neurology 28 (1973), 339-346.

[9] I. Bizzozero, D. Costato, S. Della Sala, C. Papagno, H. Spinnler and A. Venneri, Upper and lower face apraxia: Role of the right hemisphere, Brain 123 (2000), 2213-2230.

[10] M. Brazzelli, E. Capitani, S. Della Sala, H. Spinnler and M. Zuffi, A neuropsychological instrument adding to the description of patients with suspected cortical dementia: The Milan overall dementia assessment, Journal of Neurology, Neurosurgery, and Psychiatry 57 (1994), 1510-1517.

[11] A. Brun and E. Englund, Regional pattern of degeneration in Alzheimer's disease: Neuronal loss and histopathological grading, Histopathology 5 (1981), 549-564.

[12] E. De Renzi, Slowly progressive visual agnosia or apraxia without dementia, Cortex 22 (1986), 171-180.

[13] E. De Renzi Apraxia, in: Handbook of Neuropsychology, F. Boller and J. Grafman, ed., Elsevier Science Publishers B.V., Amsterdam, 1989, pp. 245-263.

[14] E. De Renzi and P. Faglioni Apraxia, in: Handbook of Clinical and Experimental Neuropsychology, G. F. Denes and L. Pizzamiglio, ed., Psychology Press, Hove, 1999, pp. 421-441.

[15] E. De Renzi, P. Faglioni and P. Sorgato, Modality-specific and supramodal mechanisms of apraxia, Brain 105 (1982), 301-312.

[16] E. De Renzi, F. Motti and P. Nichelli, Imitating gestures: a quantitative approch to ideomotor apraxia, Archives of $\mathrm{Neu}$ rology 37 (1980), 6-10.

[17] E. De Renzi, A. Pieczuro and L.A. Vignolo, Oral apraxia and aphasia, Cortex 2 (1966), 50-73.

[18] S. Della Sala, M. Laiacona, C. Trivelli and H. Spinnler, Poppelreuter-Ghent overlapping figures test, Its sensitivity to age, and its clinical use, Archives of Clinical Neuropsychology 10 (1995), 511-534.

[19] S. Della Sala, L. Lorenzi, H. Spinnler and M. Zuffi, Component of the breakdown of verbal communication in Alzheimer's disease, Aphasiology 7 (1993).

[20] S. Della Sala, F. Lucchelli and H. Spinnler, Ideomotor apraxia in patients with dementia of Alzheimer type, Journal of Neurology 234 (1987), 91-93.

[21] S. Della Sala, S. Muggia, H. Spinnler and M. Zuffi, Cognitive modelling of face processing: Evidence from Alzheimer patients, Neuropsychologia 33 (1995), 675-687.

[22] S. Della Sala, H. Spinnler and C. Trivelli, Slowly progressive impairment of spatial exploration and viual perception, Neurocase 2 (1996), 299-323.

[23] S. Della Sala, H. Spinnler and A. Venneri, Un nuovo test di aprassia della faccia superiore ed inferiore: dati normativi e validazione su cerebrolesi sinistri e dementi di Alzheimer [A test of face Apraxia: norms and validation with a sample of focal brain damaged patients and a sample of patients with Alzheimer's disease], Archivio di Psicologia, Neurologia e Psichiatria 49 (1988), 346-357.

[24] N. Dobigny-Roman, B. Dieudonne-Moinet, D. Tortrat, M. Verny and B. Forette, Ideomotor apraxia test: a new test of imitation of gestures for elderly people, European Journal od Neurology 5 (1998), 571-578.

[25] D.F. Edwards, R.K. Deuel, C.M. Baum and J.C. Morris, A quantitative analysis of apraxia in senile dementia of the Alzheimer type: stage-related difference in prevalence and type, Dementia 2 (1991), 142-149. 
[26] N.L. Foster, T.N. Chase, N.J. Patrons, M.M. Gillespie and P. Fedio, Cerebral mapping of apraxia in Alzheimer's disease by positron emission tomography, Annals of Neurology 19 (1986), 139-143.

[27] N. Geschwind, The apraxias: Neural mechanisms of disorders of learned movements, American Scientist 63 (1975), 188195.

[28] K.M. Heilman, L. Rothi and A. Kertesz, Localization of apraxia-producing lesions, in: Localization in Neuropsychology, A. Kertesz, ed., Academic Press, San Diego, 1983, pp. 371-389.

[29] J.R. Hodges, N. Graham and K. Patterson, Charting the progression in semantic dementia: Implications for the organisation of semantic memory, Memory 3 (1995), 463-495.

[30] J.C. Johnston, D.M. Resenbaum, C.M. Picone and J.C. Grottam Apraxia of eyelid opening secondary to right hemisphere infarctionm Annals of Neurology 25 (1989), 622-624.

[31] D.A. Kareken, F. Unverzagt, K. Caldemeyer, M.R. Farlow and G.D. Hutchins, Functional brain imaging in apraxia, Archives of Neurology 55 (1998), 107-113.

[32] A. Kertesz and P. Hooper, Praxis and language: the extent and variety of apraxia in aphasia, Neuropsychologia 20 (1982), 275-286.

[33] E. Kokmen, F.S. Ozemekci, R.H. Cha and P.J. O'Brien, Testing for apraxia in neurological patients: a descriptive study in two diverse cultures, European Journal of Neurology 5 (1998), $175-180$.

[34] J.H. Kramer and J.M. Duffy Aphasia, apraxia and agnosia in the diagnosis of dementia, Dementia 7 (1996), 23-26.

[35] A.E. Lang, Cortical basal ganglionic degeneration presenting with progressive loss of speech output and orofacial dyspraxia, Journal of Neurology, Neurosurgery and Psychiatry 55 (1992), 1101.

[36] Y. Lebrun, Apraxie de la parole et apraxie bucco-faciale [Speech apraxia and oral apraxia], in: Solal, Marseille, L'apraxie, D. Le Gall and G. Aubin, ed., 1994, pp. 160-182.

[37] M. Lewandowski Ũber apraxie des LidschluBes [About lid apraxia], Berliner Klinische Wochenschrift 29 (1907), 921923.

[38] M. Lezak, Neuropsychological assessment, Chapter 16: Executive functions and motor performance, 3rd Edition ed., Oxford University Press, New York, 1995, 650-685.

[39] F. Lucchelli, O. Lopez, P. Faglioni and F. Boller, Ideomotor and ideational apraxia in Alzheimer's disease, International Journal of Geriatric Psychiatry 8 (1993), 413-417.

[40] H. Marcuse, Apraktische Symptome bei einem Fall von seniler Demenz [Apraxia in a case of senile dementia], Centralblatt fü Nervenheilkunde und Psychiatrie 15 (1904), 737-751.

[41] P. Marie, Presentation de malades atteints d'anarthrie par lesion de l'hemisphere gauche du cerveau [Description of patients with anarthria following lesion of the left hemisphere], Bulletins et Memoires de la Societe de Medicine des Hopitaux (1907), 864-865.

[42] T.P. Marquardt and H. Sussman, The elusive lesion: apraxia of speech link in Broca's aphasia, in: Apraxia of speech: Physiology, acoustics, linguistics, management, J.C. Rosenbeck, M.R. McNeil and A.E. Aronson, ed., College Hill Press, San Diego, 1984, pp. 91-112.

[43] G. McKhann, D. Drachman, M. Folstein, R. Katzman, D. Price and E.M. Stadlan, Clinical diagnosis of Alzheimer's disease: Report of the NINCDA-ADRDA Work Group under the auspices of Department of Health and Human Services Task Force on Alzheimer's Disease, Neurology 34 (1984), 939-944.
[44] T. Mintz, Lesion size and localization in limb and buccofacial apraxia: retrospective analysis, University of Western Ontario, London, 1989.

[45] J.P. Mohr, M.S. Pessin, S. Finkelstein, H.H. Funkenstein, G.W. Duncan and K. Davies Broca aphasia: Pathology and Clinical, Neurology 28 (1978), 311-324.

[46] F. Moutier, L'aphasie de Broca [Broca's aphasia], Steheil, Paris, 1908.

[47] B. Okuda, H. Tachibana, K. Kawabata, M. Takeda and M. Sugita, Slowly progressive limb-kinetic apraxia with a decrease in unilateral cerebral blood flow, Acta Neurologica Scandinavica 86 (1992), 76-81.

[48] M.V. Perea and V. Ladera, Interaction between neuropsychological deficit in execution-performance and ability to carry out daily activities in Alzheimer type dementia, Revista de Neurologia 25 (1997), 513-518.

[49] L.H. Phillips, S. Della Sala and C. Trivelli, Fluency deficits in patients with Alzheimer's disease and frontal lobe lesions, European Journal of Neurology 3 (1996), 102-108.

[50] H. Pineas Klinischer und anatomischer Befund eines Falles von CO-Vergiftung, Ein beitrag zur Frage der psychomotorischen Apraxie und verwandter Bewegungsstoerungen [Clinical and anatomical abservations in a case of $\mathrm{CO}$ poisoning. A case report on psychomotor apraxia and related movement disorders], Zeitschrift fü die gesamte Neurologie und Psychiatrie 93 (1924), 36-54.

[51] K. Poeck, Clues to the nature of disruption to limb praxis, in: Neuropsychological studies of apraxia and related disorders, E.A. Roy, ed., Elsevier, North-Holland, 1985, pp. 99-109.

[52] K. Poeck and M. Kerschensteiner, Analysis of sequential motor events in oral apraxia, in: Otfried Foster Symposium, K. Zulch, O. reutzfeld and G. Galbraith, ed., Springer, Berlin, 1975, pp. 98-109.

[53] P.P. Pramstaller and C.D. Marsden, The basal ganglia and apraxia, Brain 119 (1996), 319-340.

[54] A.S. Raade, L.J.G. Rothi and K.M. Heilman, The relationship between buccofacial and limb apraxia, Brain and Cognition 16 (1991), 130-146.

[55] S.Z. Rapcsak, S.C. Croswell and A.B. Rubens, Apraxia in Alzheimer's disease, Neurology 39 (1989), 664-668.

[56] L.J.G. Rothi and K.M. Heilman, Introduction to limb apraxia, in: Apraxia. The Neuropsychology of Action, L.J.G. Rothi and K.M. Heilman, ed., Psychology Press, Hove, 1997, pp. 1-6.

[57] B. Ska, Manifestations apraxiques dans la demence de type Alzheimer, in: L'Apraxie, D. Le Gall and G. Aubin, ed., Solal, Marseille, 1994, pp. 122-129.

[58] H. Spinnler and G. Tognoni, Standardizzazione e taratura italiana di test neuropsicologici, Italian Journal of Neurological Sciences 6 (1987), 1-120.

[59] P.A. Square, E.A. Roy and R.E. Martin, Apraxia of speech: Another formof praxis disruption, in: Apraxia. The Neuropsychology of Action, L.J.G. Rothi and K.M. Heilman, ed., Psychology Press, Hove, 1997, pp. 173-206.

[60] P. Square-Storer, Acquired Apraxia of Speech in Aphasic Adults, LEA, Hove, 1989.

[61] P. Square-Storer and E.A. Roy, The apraxias: commonalities and distinctions, in: Acquired apraxia of speech in aphasic adults: theoretical and clinical issue, P. Square-Storer, ed., L.E.A., Hove, 1989, pp. 20-63.

[62] R. Taylor, Motor apraxia in dementia, Perceptual and Motor Skills 79 (1994), 523-528.

[63] G. Tognola and L.A. Vignolo, Brain lesions associated with oral apraxia in stroke patients: a clinico-neuroradiological 
investigation with CT scan, Neuropsychologia 18(1980), 257272.

[64] A. Travniczek-Marterer, W. Danielczyk, M. Simanyi and P. Fischer, Ideomotor apraxia in Alzheimer's disease, Acta Neu rologica Scandinavica 88 (1993), 1-4.

[65] P.J. Tyrrell, L.D. Kartsounis, R.S.J. Frackowiak, L.J. Findley and M.N. Rossor, Progressive loss of speech output and orofacial dyspraxia associated with frontal lobe hypometabolism, Journal of Neurology, Neurosurgery and Psychiatry 54 (1991), 351-357.

[66] P.J. Tyrrell, E.K. Warrington, R.S.J. Frackowiak and M.N. Rossor, Heterogeneity in progressive aphasia due to focal cortical atrophy: a clinical and PET study, Brain 113 (1990), 1321-1326.
[67] A. Venneri, R. Pentore, B. Cotticelli and S. Della, Sala Unilateral spatial neglect in late stage of Alzheimer's disease, Cortex 34 (1998), 743-752.

[68] R.T. Watson, W.S. Fleet, L. Gonzalez-Rothi and K.M. Heilman, Apraxia and the supplementary motor area, Archives of Neurology 43 (1986), 787-792.

[69] L. Willis, M. Beherens, W. Mack and H. Chui, Ideomotor apraxia in early Alzheimer's disease: time and accuracy measures, Brain and Cognition 38 (1998), 220-233.

[70] J.A. Yesavage, J.O. Brooks, J. Taylor and J. Tinklenberg, Development of aphasia, apraxia and agnosia, and decline in Alzheimer's disease, American Journal of Psychiatry 150 (1993), 742-747. 


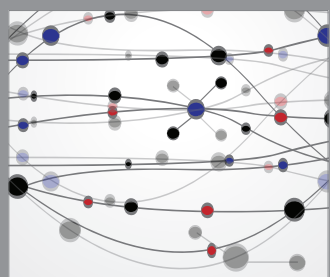

The Scientific World Journal


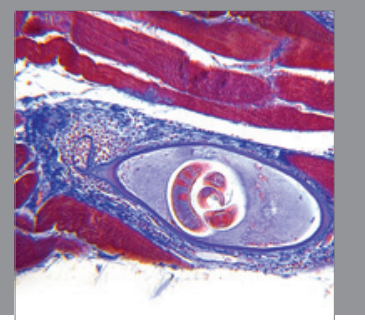

Gastroenterology

Research and Practice
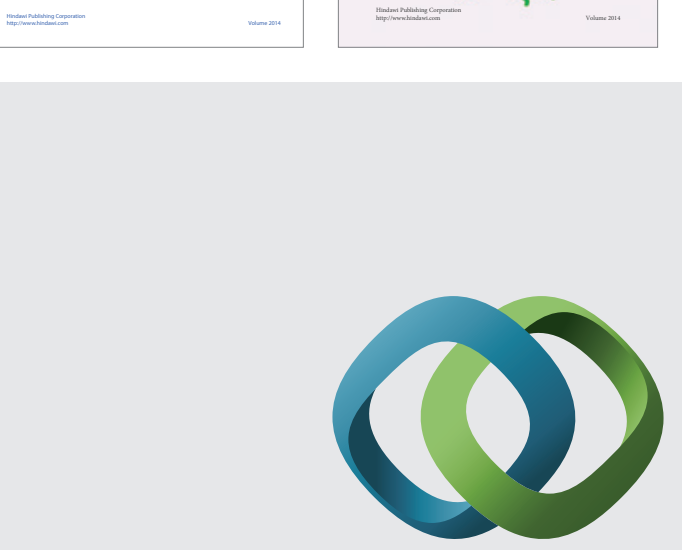

\section{Hindawi}

Submit your manuscripts at

http://www.hindawi.com
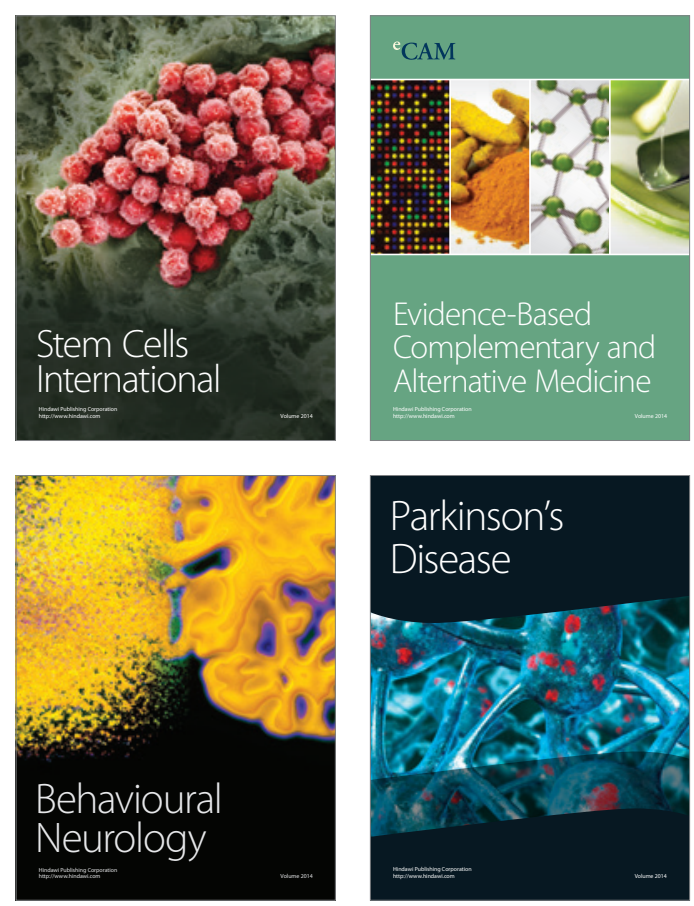

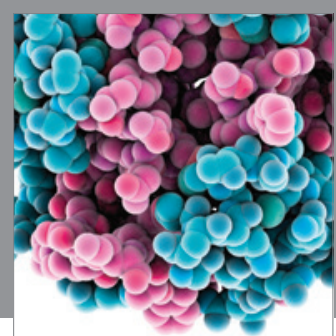

Journal of
Diabetes Research

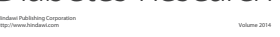

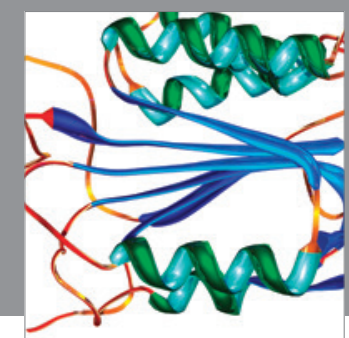

Disease Markers
